\title{
STUDENTS' HEALTH LEVEL AS A RESULT OF THEIR LIFESTYLE
}

D0I: 10.36740/WLek202104111

\author{
Grygoriy P. Griban' ${ }^{1}$, Natalia A. Lyakhova ${ }^{2}$, Alla M. Harlinska', Tetiana Ye. Yavorska', Nataliia Ye. Kolesnyk', \\ Serhii M. Hryshchuk', Oksana V. Obodzinska ${ }^{3}$ \\ 'ZHYTOMYR IVAN FRANKO STATE UNIVERSITY, ZHYTOMYR, UKRAINE \\ ¿UKRAINIAN MEDICAL STOMATOLOGICAL ACADEMY, POLTAVA, UKRAINE \\ ${ }^{3}$ POLISSIA NATIONAL UNIVERSITY, ZHYTOMYR, UKRAINE
}

\begin{abstract}
The aim: Is to study the level of knowledge, skills, abilities, and health indicators of students during the formation of their healthy lifestyle. Materials and methods: The research was conducted at Zhytomyr Ivan Franko State University and Polissya National University in 2018-2020. Thus, 882 students (385 males and 497 females) of different specialties between the ages of 17 and 23 were examined. To assess the level of knowledge, skills, and abilities of students during the formation of a healthy lifestyle, a survey was conducted. The health level of students was assessed by the method of the qualitative express assessment of the physical health level, which made it possible to assess the dynamics of the quality of forming a healthy lifestyle.

Results: It was found that only $5.7 \%$ of male and $6.4 \%$ of female students had a high level of knowledge of all the health components; only $7.0 \%$ of male and $8.3 \%$ of female students had a high level of knowledge about the factors of health formation and skills in using them both during training and future professional activity; $20.3 \%$ of male and $14.7 \%$ of female students did not have knowledge about the negative impact of bad habits on health; $19.3 \%$ of male and $18.3 \%$ of female students did not know the components of a healthy lifestyle at all; $17.9 \%$ of male and $21.7 \%$ of female students did not have motivational attitudes towards a healthy lifestyle and did not know how to form them. It was found that most of the indices of both male and female students that characterize the level of students' health deteriorated significantly during their studies ( $p<0.05-0.001)$. Conclusions: The research showed that most students (both males and females) did not follow a healthy lifestyle. It was reflected in the low health level of most students and the negative dynamics of the indices that characterize the level of health in the process of studying. All this requires taking into account the features of forming a healthy lifestyle of students in physical education classes at higher education institutions.
\end{abstract}

KEY WORDS: health, healthy lifestyle, physical education, students

Wiad Lek. 2021;74(4):874-879

\section{INTRODUCTION}

The problem of forming, maintaining, and strengthening health has always been important for humans and has been the subject of medical and biological, psychological and pedagogical, and social and philosophical research $[1,2,3]$. Maintaining health, preventing diseases, and following a healthy lifestyle have always depended on the development level of the society. The formation of students' understanding and belief that health is the highest value of a person, which must be preserved and maintained continuously, requires a certain educational work during sports and health and fitness activities $[4,5]$.

Studying the psychological and pedagogical aspects of the formation of students' to health, scientists $[6,7]$ have developed criteria that are characteristics of their components, namely: the orientation of health needs, the ability to assess personal psychophysical qualities, the skills in operating specific health tools, and the creative approach to the choice of the physical activity forms. The orientation to the health values of students is formed taking into account the following psychological and pedagogical conditions: the orientation of students to the reproduction and development of valeological values; strengthening health functions in the areas of education and leisure of students; the creative attitude to the use of modern approaches in valeological and vocational education; the intensification of the development, expansion, and enrichment of the orientations of future specialists, including them in creative physical fitness and health activities $[8,9]$.

The scientific research $[10,11]$ proved that regular exercises, which is one of the main factors of a healthy lifestyle, should be taken throughout life. A special stage for a large number of people, the future elite, is studentship. Young students have always been characterized by a high level of intellectual development, the desire to acquire professional knowledge, social independence, and high motor activity. In studentship, the age formation of an organism comes to an end, motor and vegetative functions reach the highest interaction and development. The studentship is considered to be the final stage of the progressive age development of motor and mental functions. That is why in this period of biological development, the body of students is quite flexible and highly-adaptive to physical exercises. In this period of human development, physical exercises are the 
Table I. The level of knowledge, skills, and abilities of the HEl students to maintain their own health ( $n=385$ males; $n=497$ females, $\%$ )

\begin{tabular}{|c|c|c|c|c|c|c|}
\hline \multirow{2}{*}{ The factors of health formation } & \multirow{2}{*}{ Gender } & \multicolumn{5}{|c|}{ Levels } \\
\hline & & High & Sufficient & Middle & Low & Poor \\
\hline \multirow{2}{*}{ The components of health } & males & 5.7 & 16.6 & 38.7 & 21.8 & 17.2 \\
\hline & females & 6.4 & 21.9 & 32.1 & 21.3 & 18.3 \\
\hline \multirow{2}{*}{ The main factors of health formation } & males & 7.0 & 17.9 & 39.5 & 24.2 & 11.4 \\
\hline & females & 8.3 & 23.5 & 41.5 & 16.9 & 9.8 \\
\hline \multirow{2}{*}{ Bad habits and dangerous factors } & males & 8.1 & 20.5 & 43.9 & 20.3 & 6.7 \\
\hline & females & 9.9 & 25.6 & 41.3 & 14.7 & 8.5 \\
\hline \multirow{2}{*}{$\begin{array}{c}\text { The causes of diseases and loss of } \\
\text { working capacity }\end{array}$} & males & 5.6 & 15.8 & 39.7 & 24.9 & 14.0 \\
\hline & females & 6.2 & 22.9 & 32.3 & 21.1 & 17.5 \\
\hline \multirow{2}{*}{ Motor activity and its means } & males & 7.6 & 17.4 & 44.5 & 25.7 & 4.8 \\
\hline & females & 7.7 & 24.4 & 33.2 & 18.9 & 15.8 \\
\hline \multirow{2}{*}{$\begin{array}{l}\text { Self-assessment of body state and } \\
\text { health }\end{array}$} & males & 7.8 & 18.7 & 43.4 & 23.4 & 6.7 \\
\hline & females & 8.7 & 24.7 & 42.5 & 16.3 & 7.8 \\
\hline
\end{tabular}

most important means of physical and mental health, the natural and biological basis for the harmonious development of personality, and effective life $[12,13]$.

\section{THE AIM}

The aim of this study is to investigate the level of knowledge, skills, abilities, and health indicators of students during the formation of a healthy lifestyle.

\section{MATERIALS AND METHODS}

The research was conducted at Zhytomyr Ivan Franko State University (ZSU) and Polissya National University (PNU) in 2018-2020. Thus, 882 students (385 males and 497 females) of different specialties between the ages of 17 and 23 were examined. To assess the level of knowledge, skills, and abilities of students during the formation of a healthy lifestyle, a survey and expert assessment of the students' of higher education institutions (HEI) knowledge, skills, and abilities to maintain their own health and adhere to the rules and norms of a healthy lifestyle (HLS) were conducted. The health level of students was assessed by the method of the qualitative express assessment of the physical health level (G. L. Apanasenko) [14], based on the calculated body weight, life, power, and Robinson indices and Martin-Kushelevsky test, which made it possible to assess the dynamics of the quality of forming a healthy lifestyle. The readiness of students to follow a healthy lifestyle is an integral personal formation, which is the result of purposeful training, which makes it possible to carry out personal and, in the future, professional health-improving activities. The readiness of students to implement HLS in the process of life was considered as one of the aspects of the student's readiness for personal development, and on the other hand, as the readiness for a productive life. The state of health and a healthy lifestyle were identified as the main factors determining the need for a healthy lifestyle.
The research methods included the analysis and generalization of literature sources, questionnaires, expert evaluation, testing of health indicators, methods of mathematical statistics.

\section{RESULTS}

A healthy lifestyle is a very common concept, which is interpreted by each student in their own way. Some of them consider this concept to be more physical, others spiritual. One aspect of a healthy lifestyle is maintaining one's own body in good physical condition. It is known that the health of students is affected by many factors, and the most important of them is a lifestyle - a set of sustainable forms of life activities that determine the way of life and habits. If students constantly and persistently took care of their own health from childhood, they base the life on such stable useful habits, skills, behavior, such way of thinking, perception of others and themselves, which determine their main direction - the way to health, thus, they choose a healthy lifestyle.

A healthy lifestyle involves following certain rules that ensure harmonious development, high efficiency, spiritual balance, and health. The stable concept of "a healthy lifestyle" is based on the individual system of behavior and habits of each individual, which provides one with the necessary standard of living and healthy longevity. A healthy lifestyle involves practical actions aimed at preventing diseases, strengthening all body systems, and improving general well-being. At the same time, the conducted survey and expert assessment of knowledge, skills, and abilities of the students of higher education institutions to maintain their own health showed that only $5.7 \%$ of male and $6.4 \%$ of female students had a high level of knowledge of all the components of human health, 16.6 and $21.9 \%$ respectively had a sufficient level, 38.7 and $32.1 \%$ - the middle level, and $39.0 \%$ of males and 39.6 $\%$ of females had a very low level or did not have such 
Table II. The level of knowledge, skills, and abilities of the HEl students to comply with the norms and rules of a healthy lifestyle ( $n=385$ males; $\mathrm{n}=497$ females, \%)

\begin{tabular}{|c|c|c|c|c|c|c|}
\hline \multirow{2}{*}{ The formation factors of a healthy lifestyle } & \multirow{2}{*}{ Gender } & \multicolumn{5}{|c|}{ Levels } \\
\hline & & High & Sufficient & Middle & Low & Poor \\
\hline \multirow{2}{*}{ Components of a healthy lifestyle } & males & 10.1 & 21.8 & 48.8 & 15.9 & 3.4 \\
\hline & females & 9.3 & 20.9 & 51.5 & 13.9 & 4.4 \\
\hline \multirow{2}{*}{$\begin{array}{l}\text { Motivational and values-based attitude to a } \\
\text { healthy lifestyle }\end{array}$} & males & 9.6 & 22.1 & 50.4 & 11.2 & 6.7 \\
\hline & females & 7.9 & 18.7 & 51.7 & 16.5 & 5.2 \\
\hline \multirow{2}{*}{$\begin{array}{l}\text { Psychological and pedagogical determinants of } \\
\text { a healthy lifestyle formation }\end{array}$} & males & 8.1 & 19.4 & 48.8 & 16.4 & 7.3 \\
\hline & females & 6.8 & 16.9 & 51.8 & 18.3 & 6.2 \\
\hline \multirow{2}{*}{$\begin{array}{c}\text { Knowledge and skills in forming a healthy } \\
\text { lifestyle }\end{array}$} & males & 9.1 & 22.3 & 51.2 & 12.7 & 4.7 \\
\hline & females & 9.7 & 19.5 & 54.1 & 12.9 & 3.8 \\
\hline \multirow{2}{*}{ Health and fitness technologies } & males & 7.5 & 16.6 & 43.4 & 25.5 & 7.0 \\
\hline & females & 6.1 & 16.4 & 47.2 & 22.7 & 7.6 \\
\hline
\end{tabular}

Table III. The dynamics of the physical health indicators of the HEl students during two years of study $(n=882, X \pm m)$

\begin{tabular}{|c|c|c|c|c|c|}
\hline HEI & Gender & $\begin{array}{c}\text { The beginning of the } 2018 \\
\text { academic year }\end{array}$ & $\begin{array}{c}\text { The end of the } 2020 \\
\text { academic year }\end{array}$ & $\mathbf{t}$ & $\mathbf{p}$ \\
\hline \multicolumn{6}{|c|}{ Body mass index, $\mathrm{kg} / \mathrm{m}^{2}$} \\
\hline \multirow{2}{*}{ ZSU } & males $(n=138)$ & $23.1 \pm 0.16$ & $24.4 \pm 0.18$ & 5.40 & $<0.001$ \\
\hline & females $(n=273)$ & $21.9 \pm 0.10$ & $23.0 \pm 0.12$ & 7.04 & $<0.001$ \\
\hline \multirow{2}{*}{ PNU } & males $(n=247)$ & $23.3 \pm 0.12$ & $24.2 \pm 0.14$ & 4.88 & $<0.001$ \\
\hline & females $(n=224)$ & $21.7 \pm 0.11$ & $22.7 \pm 0.13$ & 6.46 & $<0.001$ \\
\hline \multicolumn{6}{|c|}{ Life index, $\mathrm{ml} / \mathrm{kg}$} \\
\hline \multirow{2}{*}{ ZSU } & males $(n=138)$ & $55.7 \pm 0.87$ & $53.9 \pm 0.90$ & 1.44 & $>0.05$ \\
\hline & females $(n=273)$ & $45.1 \pm 0.64$ & $42.8 \pm 0.67$ & 2.48 & $<0.05$ \\
\hline \multirow{2}{*}{ PNU } & males $(n=247)$ & $55.9 \pm 0.78$ & $54.1 \pm 0.75$ & 1.66 & $>0.05$ \\
\hline & females $(n=224)$ & $44.9 \pm 0.56$ & $43.1 \pm 0.54$ & 2.31 & $<0.05$ \\
\hline \multicolumn{6}{|c|}{ Power index, \% } \\
\hline \multirow{2}{*}{ ZSU } & males $(n=138)$ & $60.1 \pm 0.69$ & $56.9 \pm 0.66$ & 3.35 & $<0.001$ \\
\hline & females $(n=273)$ & $40.5 \pm 0.48$ & $37.4 \pm 0.51$ & 4.43 & $<0.001$ \\
\hline \multirow{2}{*}{ PNU } & males $(n=247)$ & $60.3 \pm 0.52$ & $57.7 \pm 0.49$ & 3.64 & $<0.001$ \\
\hline & females $(n=224)$ & $40.7 \pm 0.50$ & $38.6 \pm 0.54$ & 2.85 & $<0.01$ \\
\hline \multicolumn{6}{|c|}{ Robinson index, c. u. } \\
\hline \multirow{2}{*}{ ZSU } & males $(n=138)$ & $94.9 \pm 0.76$ & $95.3 \pm 0.78$ & 0.83 & $>0.05$ \\
\hline & females $(n=273)$ & $94.7 \pm 0.58$ & $95.4 \pm 0.60$ & 0.84 & $>0.05$ \\
\hline \multirow{2}{*}{ PNU } & males $(n=247)$ & $94.5 \pm 0.62$ & $95.0 \pm 0.64$ & 0.56 & $>0.05$ \\
\hline & females $(n=224)$ & $94.2 \pm 0.52$ & $95.0 \pm 0.55$ & 1.06 & $>0.05$ \\
\hline \multicolumn{6}{|c|}{ Martin-Kushelevsky test, s } \\
\hline \multirow{2}{*}{ ZSU } & males $(n=138)$ & $131.2 \pm 0.88$ & $136.1 \pm 0.79$ & 4.14 & $<0.001$ \\
\hline & females $(n=273)$ & $137.5 \pm 0.81$ & $142.8 \pm 0.85$ & 4.51 & $<0.001$ \\
\hline \multirow{2}{*}{ PNU } & males $(n=247)$ & $129.7 \pm 0.75$ & $133.6 \pm 0.78$ & 3.60 & $<0.001$ \\
\hline & females $(n=224)$ & $134.4 \pm 0.79$ & $139.5 \pm 0.82$ & 4.48 & $<0.001$ \\
\hline
\end{tabular}

knowledge at all (Table I). Similar results were shown by students in the research of students' knowledge about the factors of health formation, which found that only $7.0 \%$ of males and $8.3 \%$ of females had a high level of such knowledge, skills, and abilities and could use them both during the study and professional and life activities. At 
the same time, $35.6 \%$ of males and $26.7 \%$ of females did not have such knowledge and did not know what factors can affect their health positively. A very large number of students did not know the impact of bad habits, dangerous factors, the causes of diseases, and the role of physical activity in their prevention. It was also found that $26.5 \%$ of male and $33.4 \%$ of female students could self-assess their health at a high and sufficient level and at the same time $30.1 \%$ of males and $24.1 \%$ of females had low and poor levels of knowledge and were unable to assess their own health.

This indicates that the existing system of physical education of students can not fully solve the problems that would change the attitude of students to their own way of life. The aim of physical education, in addition to the formation of motor skills, abilities, and physical qualities, should be educational work. The purpose of such educational work should be aimed not only at the period of studying at HEI but, above all, at students' further life and should promote the formation of positive attitudes to the factors that improve health and negative attitudes to bad habits and excess weight and obesity.

At the same time, our research showed that $19.3 \%$ of male and $18.3 \%$ of female students did not know the components of a healthy lifestyle at all; $17.9 \%$ and $21.7 \%$ respectively did not have motivational attitudes to a healthy lifestyle and did not know how to form them (Table II). Accordingly, such students do not have the need to form a healthy lifestyle, they lack the knowledge and skills how to do it or appropriate physical culture and health technologies to improve their own health.

In order to check the effectiveness of students' compliance with a healthy lifestyle and assess their health, the method of G. L. Apanasenko was used. Thus, the analysis of the body mass index showed that its dynamics had a negative trend: the body mass index of both male and female students deteriorated significantly during the 1 st - 2nd years of study $(\mathrm{p}<0.001)$ (Table III). It indicated the low efficiency of health and fitness activities. In particular, classes were held only in the second year once a week at ZSU in 2018-2019, and only in the first year for one term in the 2019-2020 academic year. In terms of PNU, classes were held in the 1 st - 2nd years of study for two years. Therefore, the difference between the indicators of body mass index at the beginning and end of the study of the PNU students was smaller, in comparison to ZSU students.

The study of the life index showed that the ZSU students had a greater difference between the indicators at the beginning and end of the study and, consequently, a worse level of respiratory function. It is important to note that female students of both HEI were recorded to have more pronounced negative changes in the life index than male students: the difference between the initial and final data of the male students of both HEI was unreliable ( $p>0.05)$, and that of female students - significant $(\mathrm{p}<0.05)$.

The analysis of the power index confirmed the low efficiency of health and fitness activities at HEI, especially at ZSU, where the number of physical education classes was lower. The power capabilities of the students (both men and women) of both HEI at the beginning of the study was assessed as lower than the middle, and at the end of the study - as low. The analysis of the Robinson index showed that it tended to deteriorate concerning the students (both men and women) of both HEI, but no significant difference between student performance at the beginning and end of the study was found $(p>0.05)$.

The study of the results of the Martin-Kushelevsky test (heart rate recovery after 20 squats in $30 \mathrm{~s}$ ) showed a significant $(p<0.001)$ difference between the indicators before and after the study; the indicators of the heart rate recovery duration of the students of all groups were found to be significantly lower than they were at the beginning, which indicated a deterioration in the effectiveness of students' recovery processes. It proved the lack of effectiveness of the modern physical education process at HEI in terms of promoting the health of students and the formation of their healthy lifestyle.

\section{DISCUSSION}

Scientists have different interpretations of health. Some scientists $[2,3,15]$ present health as a state with constantly changing environmental conditions in relation to the adaptive capacity of the human body. Other scientists $[4,7]$ consider health as a set of abilities of an individual and the features of one's behavior, which can be used to determine the liability to diseases, while health is the sum of the reserve capabilities of the main functional systems of the human body. At the same time, every year the health status of young people deteriorates by an average of 10-15\%, the level of physical and mental health decreases, the socio-cultural values of physical education are leveled [ 1 , 13]. The deterioration of students' health is also associated with detraining, stress, negative environmental impact, failure to perform ergonomics, the lack of physical activity, resulting in an increase in the number of students with disabilities $[5,9,11]$.

The study of the compliance with and formation of a healthy lifestyle by students has many different interpretations and recommendations. It indicates that there is no single way to maintain a healthy lifestyle and active life. To form an attitude to a healthy lifestyle and its observance by students both during their studies at HEI and in later life, it is necessary to begin with the assessment of the availability of knowledge and skills in following a healthy lifestyle; the assessment of health status, the presence of bad habits, diseases, and disorders of the musculoskeletal system and the ways to eliminate them; the awareness of each student of the need to maintain a healthy lifestyle, showing interest in specific types of its manifestation; the assessment of students' activity in terms of meeting the requirements of a healthy lifestyle; the implementation of health measures in life; the formation of a positive attitude of students to the means of physical culture and sports and the discipline of Physical Education; the formation 
of a psychological attitude to maintaining high motor activity, a negative attitude towards bad habits, excess weight, etc.; the identification of the types of physical activity that meet the individual capabilities of students and their temperaments best; building confidence that the time spent exercising is compensated by good health; goal setting and compliance with it, despite fatigue, the lack of time, bad weather, etc.; the availability of different options for individual programs of physical culture and health-improving classes.

\section{CONCLUSIONS}

1. The modern system of physical education at HEI should provide training of students in terms of the formation of a healthy lifestyle by educating conscious responsibility for their own health, personality-oriented choice of goals, means, and methods of its correction taking into account their own needs and motivation, promoting health, free and conscious choice of physical culture and health technologies of training and the awareness of one's own responsibility for the realization of this choice.

2. The process of teaching students to form a healthy lifestyle is considered as a special combination of internal factors of physical culture: morphofunctional, psychological, physical, and personal developments and external factors characteristic of modern conditions of physical education and optimization of the physical education at HEI in the direction of preservation, strengthening, and formation of the health of students.

3. Psychological and pedagogical conditions for the formation of students' healthy lifestyle are the creation of a healthy educational environment as a space of individual opportunities to choose the physical activity for physical development, physical fitness, health promotion, and the effective forms of physical culture and health-promoting activities; the formation of a conscious motivational and values-based attitude of students to participate in sports and health and fitness activities and a stable need for physical self-improvement; taking into account the age and individual characteristics of students, improving the pedagogical competence of physical education teachers as a factor in mastering health-preserving learning technologies.

\section{REFERENCES}

1. Mozolev 0., Bloshchynsky I., Alieksieiev 0 . et al. Influence of modern fitness technologies on the state of health and development of motor abilities of 17-19-year-old female students. Journal of Physical Education and Sport. 2019; 19(3): 917-924. doi:10.7752/jpes.2019. s3132.

2. Prontenko K., Griban G., Aloshyna A. et al. The physical development and functional state as the important components of the students' health. Wiad. Lek. 2019; 72(12): 2348-2353. doi: 10.36740/WLek201912115.

3. Gruzieva T., Galiienko L., Pelo I. et al. Health and lifestyle of students' youth: status, problems and ways of solution. Wiad Lek. 2018; 71(9): 1753-1758.
4. Prontenko K., Griban G., Dovgan N. et al. Students' health and its interrelation with physical fitness level. Sport Mont. 2019; 17(3): 41-46. doi 10.26773/smj.191018.

4. Griban G., Lyakhova N., Tymoshenko 0. Current state of students'health and its improvement in the process of physical education. Wiad. Lek. 2020; 73(7): 1438-1447. doi: 10.36740/WLek202007124.

5. Zhamardiy V., Shkola 0., Okhrimenko I. et al. Checking of the methodical system efficiency of fitness technologies application in students' physical education. Wiad Lek. 2020; 73 (2): 332-341. doi: 10.36740/ WLek202002125.

6. Griban G., Kobernyk 0., Terentieva N. et al. Formation of health and fitness competencies of students in the process of physical education. Sport Mont. 2020; 18(3): 73-78. doi: 10.26773/smj.201008.

7. Prysiazhniuk S., Tolubko V., Oleniev D. et al. The influence of physical activities on biological age parameters of the first-year female students from the special medical department. Journal of Physical Education and Sport. 2018; 18(2): 561-564. doi:10.7752/jpes.2018.02081.

8. Prontenko K., Griban G., Prontenko V. et al. Health improvement of cadets from higher military educational institutions during kettlebell lifting activities. Journal of Physical Education and Sport. 2018; 18(1): 298-303. doi: 10.7752/jpes.2018.01040.

9. Griban G., Prontenko K., Zhamardiy V. et al. Professional stages of a physical education teacher as determined using fitness technologies. Journal of Physical Education and Sport. 2018; 18(2): 565-569. doi:10.7752/jpes.2018.02082.

10. Prontenko K., Bloshchynskyi l., Griban, G. et al. Formation of readiness of future physical culture teachers for professional activity. Universal Journal of Educational Research. 2019; 7(9): 1860-1868. doi: 10.13189/ ujer.2019.070903.

11. Griban G., Yavorska T., Tkachenko P. et al. Motor activity as the basis of a healthy lifestyle of student youth. Wiad. Lek. 2020; 73(6): 1199-1206. doi: 10.36740/WLek202006123.

12. Prontenko K., Griban G., Bloshchynskyi I. et al. Improvement of students' morpho-functional development and health in the process of sport-oriented physical education. Wiad Lek. 2020; 73(1): 161-168. doi: 10.36740/WLek202001131.

13. Griban G., Tymoshenko 0., Arefiev V. et al. (2020). The role of physical education in improving the health status of students of special medical groups. Wiad. Lek. 2020; 73 (3): 534-540. doi: 10.36740/ WLek202003125.

14. Apanasenko G. L. Knygha o zdorovj'e [Health Book]. Kyev: Medknygha; 2007: 132 p. (In Russian).

15. Mozolev 0., Bloshchynskyi I., Prontenko K. et al. Influence of fitness techniques integration on the development of physical qualities and morpho-functional state of adult females. Human Movement. 2021; 22(1): 57-65. https://doi.org/10.5114/hm.2021.98465.

\section{ORCID and contributionship:}

Grygoriy P. Griban: 0000-0002-9049-1485 A,F

Natalia A. Lyakhova: 0000-0003-0503-9935 E,F

Alla M. Harlinska: 0000-0001-7859-8637 B,D

Tetiana Ye. Yavorska: 0000-0001-6104-2202 C,F

Nataliia Ye. Kolesnyk: 0000-0001-9384-9369 A,E

Serhii M. Hryshchuk: 0000-0002-5553-8110 ${ }^{D, E}$

Oksana V. Obodzinska: 0000-0002-4832-0826 ${ }^{B, C}$

\section{Conflict of interest:}

The Authors declare no conflict of interest. 


\section{CORRESPONDING AUTHOR}

Grygoriy P. Griban

Zhytomyr Ivan Franko State University

40 Velyka Berdychivska St., 10002 Zhytomyr, Ukraine

tel: +380973341092

e- mail: gribang@ukr.net

Received: 21.10 .2020

Accepted: 03.03 .2021

A - Work concept and design, B - Data collection and analysis, C - Responsibility for statistical analysis,

D-Writing the article, $\mathbf{E}$-Critical review, $\mathbf{F}$ - Final approval of the article 